Acta Psychotherapeutica 1957;5(Suppl 1):1-6

\title{
Contents, Vol. 5, Supplement 1, 1957
}

\section{INHALTSVERZEICHNIS}

Eínleílung von Prof. Dr. med. G. Benedetti Vorwort von Dr. med. M. Sírrala

I. Das Problem 14

II. A. Ausblíck auf die Literatur «Gesteigerte Lebenstüchtigkeit» «Gesteigerte Fähigkeit, Sich-selbst-zu-werden» «Gesteigerte Fähigkeit, zu genießen und glücklich zu sein» ... Anpassung» 38

B. Die exístentíelle Situation

41

III. Das Paradigma

44

Der Patient 44

Di'î Ausgangslage

B $1 / 8$ ginn der Psychotherapie 56

Die ersten zwei Monate der Psychotherapie

Panik 90

Fortsetzung der Psychotherapie

Die offene Abteilung

Die Entlassung wird erwogen

Die Arbeit beginnt

131

152

10. Hans Zimmermann in der Welt draußen

IV. Der Ort 195

Anhang 197

Literatur

200

\section{7}

17
65

14

$354-\ll$ Gesteigerte soziale 